\title{
THE ESSENTIAL ROLE OF THE ADRENAL CORTEX IN THE RESPONSE OF PLASMA FREE FATTY ACIDS, CHOLES- TEROL, AND PHOSPHOLIPIDS TO EPINEPHRINE INJECTION *
}

\author{
BY ELEAZAR SHAFRIR $\dagger$ AND DANIEL STEINBERG $\ddagger$ \\ (From the Laboratory of Cellular Physiology and Metabolism, National Heart Institute, \\ Bethesda, Md.)
}

(Submitted for publication July 17, 1959; accepted September 10, 1959)

In a previous paper (2) it was shown that in normal rats epinephrine causes an immediate elevation of plasma free fatty acid (FFA) ${ }^{1}$ levels and a delayed rise in serum cholesterol and phospholipids. The responses were similar to but smaller in magnitude than those seen in dogs (3). In the rat studies it was further shown that removal of the pituitary or of the adrenal glands abolished these responses to epinephrine completely or almost completely. The present studies in dogs were undertaken to permit a more critical evaluation of the role of the pituitary-adrenal axis in conditioning the lipid responses to epinephrine. Using dogs it has been possible to follow the time course of the epinephrine responses in individual animals. Furthermore, it has been possible to study the responses of the same animals before and after hypophysectomy or adrenalectomy and again after institution of supportive hormonal therapy.

\section{METHODS}

Male mongrel dogs (12 to $18 \mathrm{~kg}$ ) were maintained on dry meal mixed with a small supplement of meat. A measured amount of ration was offered each morning and was consumed completely within 4 hours. Control blood samples were drawn from a leg vein after an overnight fast. In studies of 24 hours' duration or less no food was allowed. In the studies lasting 3 days no food

* Presented in part at the meetings of the Federation of American Societies for Experimental Biology, April, 1959, Atlantic City, N. J. (1).

$\dagger$ Hadassah Medical Organization Research Fellow. Permanent address: Department of Biochemistry, $\mathrm{He}$ brew University-Hadassah Medical School, Jerusalem, Israel.

$\ddagger$ Requests for reprints should be addressed to Dr. Daniel Steinberg, Bethesda.

1 The following abbreviations have been used: FFA = free fatty acids ( $\equiv$ unesterified fatty acids); $\mathrm{DCA}=$ desoxycorticosterone acetate; ACTH $=$ adrenocorticotropic hormone. was allowed during the first 24 hours and regular feedings were given on the second and third days. For studies of the acute responses to epinephrine (Parke, Davis and Co.), 20 to $25 \mu \mathrm{g}$ per $\mathrm{kg}$ was injected intravenously over a period of 30 seconds and blood samples were drawn from the opposite limb at 2, 5, 10, 40 and 60 minutes. For studies of longer term responses, epinephrine in peanut oil (Parke, Davis and Co.) was injected subcutaneously and blood samples were taken at hourly intervals for 4 to 6 hours, at 8 hours and at 24 hours. Blood samples were placed in heparinized tubes containing sodium fluoride, chilled and then centrifuged. Plasma free fatty acids were determined by a modification ${ }^{2}$ of the method of Gordon (4). The plasma, instead of being lyophilized, is dehydrated by acetic anhydride added to the extraction mixture: $50 \mathrm{ml}$ acetic anhydride, $450 \mathrm{ml}$ glacial acetic acid, $300 \mathrm{ml}$ isooctane (2,2,4-trimethylpentane), $0.5 \mathrm{ml}$ concentrated sulfuric acid. One $\mathrm{ml}$ of plasma was added to $30 \mathrm{ml}$ of this extraction mixture. After 1 to 24 hours, $5 \mathrm{ml}$ of water was added, causing separation into 2 phases. The isooctane phase was washed with acidified water and an aliquot was titrated as described by Gordon. Cholesterol was determined by the method of Sperry and Webb (5), lipid phosphorus by a modification of the method of Stewart and Hendry (6), total lipids and triglycerides by the method of Bragdon (7). Blood glucose was determined by the Somogyi-Nelson method (8).

Adrenalectomies were performed by Dr. John E. Holman of the National Heart Institute, using a transperitoneal approach. For 7 to 14 days after surgery the dogs were given daily injections of cortisone (Cortone Acetate, Merck, Sharp and Dohme), $3 \mathrm{mg}$ per $\mathrm{kg}$, and desoxycorticosterone (DOCA, The Upjohn Co.), 5 to $12.5 \mathrm{mg}$ per day. The response to epinephrine was determined while the animals were on this regimen. Cortisone was then withdrawn but DCA was continued and the epinephrine response was determined again in 10 days. In some cases a third epinephrine study was carried out after reinstituting cortisone therapy for 14 days.

Hypophysectomies were performed by $\mathrm{Mr}$. Alfred G. T. Casper, using a transpharyngeal approach. No maintenance hormonal therapy was given. Response to epinephrine was studied 1 week after surgery, after 6

\footnotetext{
2 Shafrir, E. To be published.
} 


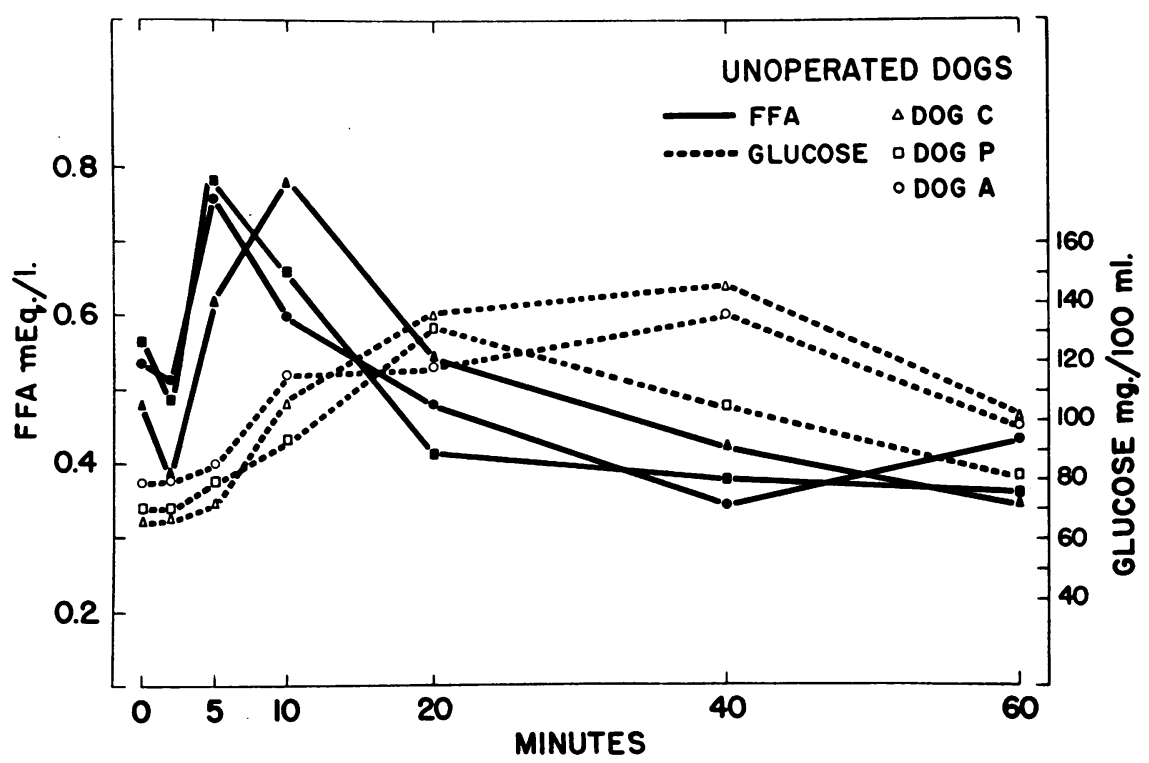

Fig. 1. Time course of FFA and glucose responses to intravenous injection of AQUEOUS EPINEPHRINE (20 TO $25 \mu \mathrm{G}$ PER KG) GIVEN AT ZERO TIME: NORMAL DOGS.

days of cortisone treatment ( 3 to $5 \mathrm{mg}$ per $\mathrm{kg}$ per day) or after 3 days of treatment with ACTH gel, 20 to 30 units per day (HP ACTHAR Gel, Armour Laboratories).

\section{RESULTS}

FF $A$ and glucose responses to intravenous epinephrine. In Figure 1 are shown the FFA and glucose response curves of normal dogs after intravenous aqueous epinephrine (20 to $25 \mu \mathrm{g}$ per $\mathrm{kg}$ ). During the first few minutes after injection the FFA levels showed a small but definite drop below the control level and only then the characteristic sharp rise to a peak at 5 to 10 minutes. This immediate transient drop in FFA level occurring after the injection of aqueous epinephrine has not been previously noted. It suggests that the rate of removal of plasma FFA is immediately increased by epinephrine and that it temporarily exceeds the rate of delivery of FFA into the plasma. The increased rate of utilization of FFA implied by these short-term observations may be due to increased muscular activity, particularly the tachycardia that begins at once. Very quickly, however, the rate of FFA delivery from adipose tissue rises and brings the plasma FFA concentration to a high level. As shown in Figure 1, FFA levels returned to control values by 20 minutes and over the next 40 minutes tended to drop very slightly below the zero time values.
The response of the blood glucose level was more sluggish, peak values being reached between 20 and 40 minutes after the injection. The time relation between the FFA curves and the glucose curves after short-acting epinephrine is similar to

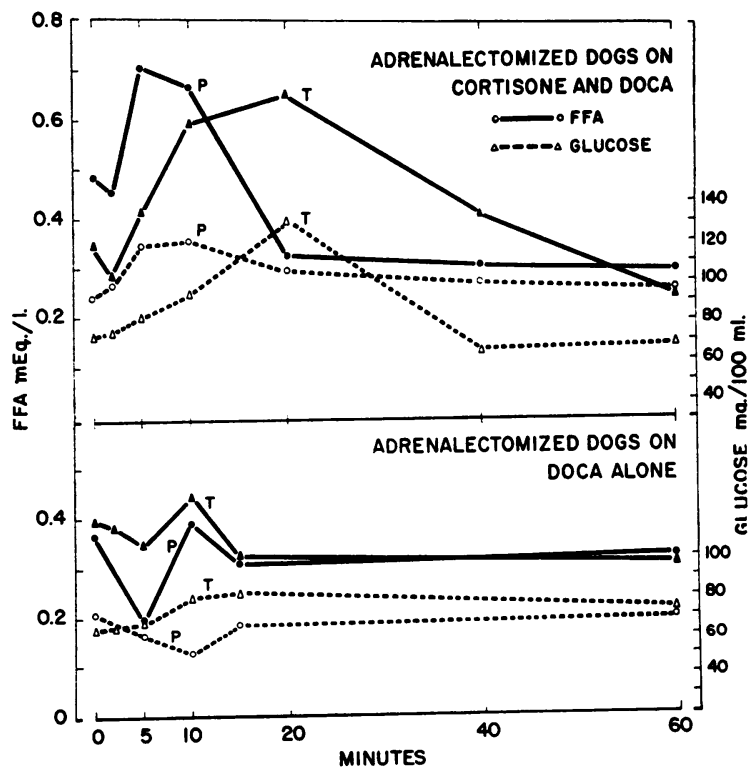

Fig. 2. Time course of FFA ANd glucose Responses TO INTRAVENOUS INJECTION OF AQUEOUS EPINEPHRINE (20 TO $25 \mu \mathrm{G}$ PER KG) GIVEN AT ZERO TIME. Lower frame: adrenalectomized dogs given DCA alone. Upper frame: same adrenalectomized dogs given cortisone therapy in addition to DCA. 


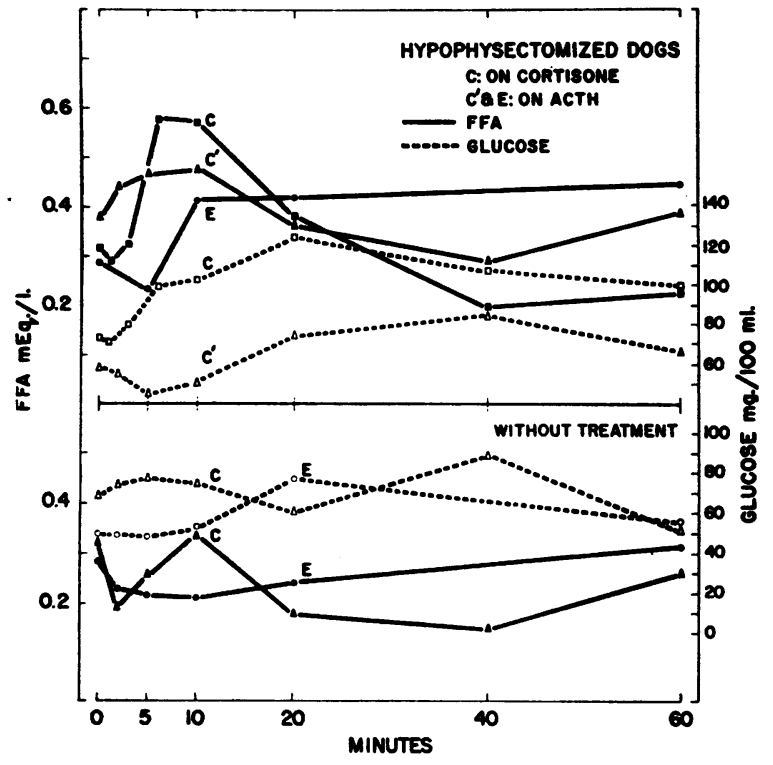

Fig. 3. Time course OF FFA AND GLUCOSE RESPONSES TO INTRAVENOUS INJECTION OF AQUEOUS EPINEPHRINE (20 TO $25 \mu \mathrm{G}$ PER KG) GIVEN AT ZERO TIME. Lower frame: hypophysectomized dogs given no treatment. Upper frame: hypophysectomized dogs given cortisone or ACTH.

the relationship observed after epinephrine in oil (3), that is, the FFA levels tend to return toward normal as the glucose levels rise toward their maximum. The probable cause and effect relationship involved has been discussed previously (3).

Adrenalectomized dogs receiving no supportive therapy other than DCA ( 5 to $12.5 \mathrm{mg}$ per day) showed no FFA response to intravenous aqueous epinephrine (lower frame, Figure 2). When they were maintained on cortisone, on the other hand (upper frame, Figure 2), the FFA response to epinephrine in these same dogs was similar to that observed prior to adrenalectomy. The response obtained in Dog $\mathrm{P}$ before operation is included in the data of Figure 1. Thus it is clear that cortisone therapy fully restores the normal FFA response. The blood glucose response, which was virtually absent in the adrenalectomized animal (lower frame, Figure 2), was partially restored by cortisone therapy but was still smaller in magnitude and more transient than the response of the intact animal.

Hypophysectomy also abolished the normal FFA response to intravenous epinephrine (lower frame, Figure 3 ). The response obtained in Dog $\mathrm{C}$ be- fore hypophysectomy is included in the data of Figure 1 and the contrast is evident. Treatment with cortisone restored the ability of the hypophysectomized animal to respond (curve $C$, upper frame, Figure 3). The peak FFA value reached was somewhat less than that reached by the intact animal but the increment over the initial value was similar. After a period of three weeks without hormonal therapy, Dog C was given ACTH (2.5 units per $\mathrm{kg}$ ) for three days and the epinephrine response was again determined (curve $C^{\prime}$, Figure 3 ). Response was partially but not completely restored. Control studies both with cortisone and with ACTH have shown that in the form and dosages used here these hormones do not of themselves have significant effects on plasma FFA levels over the time intervals studied, although under other conditions responses can be obtained (unpublished results). Supportive hormonal therapy also tended to restore the glucose response to epinephrine.

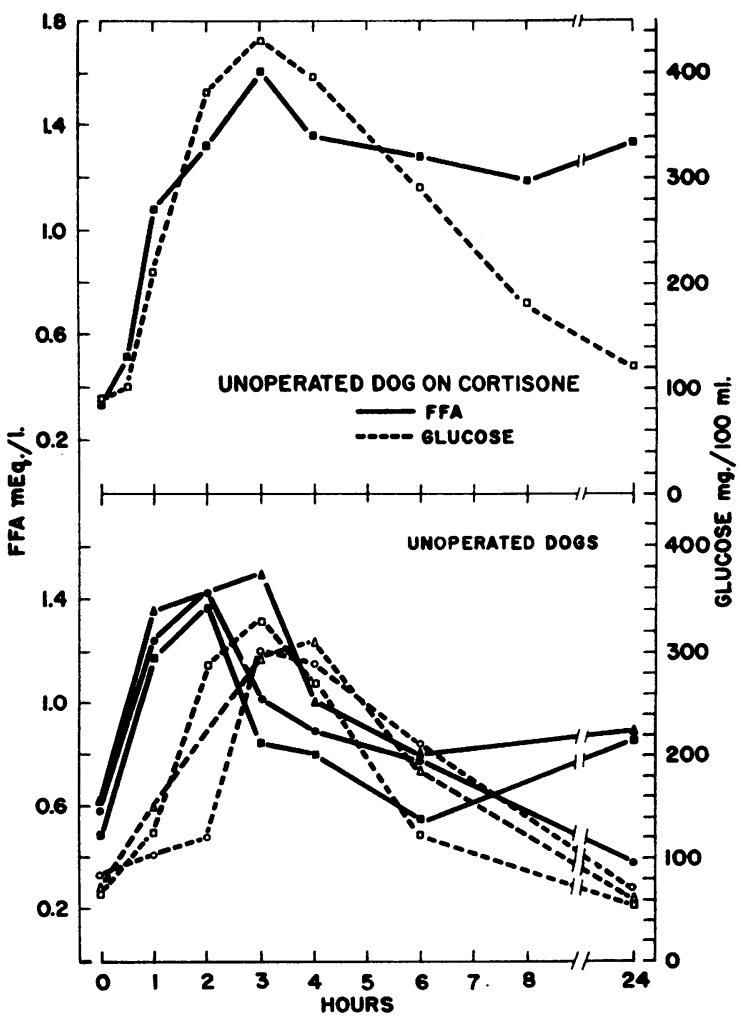

Fig. 4. Time course of FFA AND glucose Responses TO SUBCUTANEOUS INJECTION OF EPINEPHRINE IN OIL (0.6 MG PER KG). Lower frame: normal dogs. Upper frame: normal dog given simultaneous injection of cortisone ( 5 mg per $\mathbf{k g}$ ). 


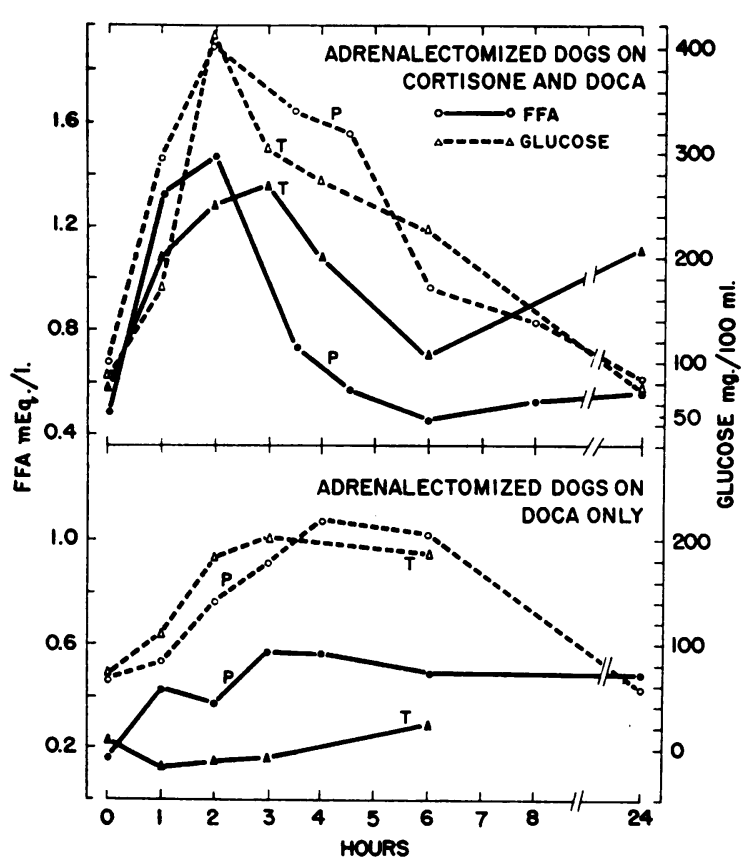

Fig. 5. Time course of FFA AND GLUCOSE Responses TO SUBCUTANEOUS IN JECTION OF EPINEPHRINE IN OIL (0.6 MG PER KG). Lower frame: adrenalectomized dogs given DCA only. Upper frame: same adrenalectomized dogs given cortisone therapy in addition to DCA.

FFA and glucose response to epinephrine in oil. The changes in plasma FFA and blood glucose levels in normal dogs over a 24 hour period following the injection of epinephrine in oil (0.6 $\mathrm{mg}$ per $\mathrm{kg}$ ) are shown in Figure 4 (lower frame). FFA levels rose to a peak at about 2 hours and then fell gradually again to reach normal values by about 6 hours.

Adrenalectomy abolished or considerably reduced the FFA response and also caused a flattening of the glucose curves (lower frame, Figure $5)$. Treatment of these same animals with cortisone (Dog $\mathrm{P}$ and $\operatorname{Dog} \mathrm{T}$ ) fully restored their ability to respond to epinephrine (upper frame, Figure 5).

Hypophysectomy also abolished the FFA response to epinephrine and abolished the glucose response as well (lower frame, Figure 6). After treatment with cortisone the peak of the FFA response was comparable in magnitude to that seen in the unoperated animals, although somewhat delayed, and the elevation persisted for a longer time. The glucose response to epinephrine was also restored by cortisone treatment but again the peak response occurred somewhat later. Treatment with ACTH, on the other hand, although it did permit a partial FFA response, appeared to be less effective than cortisone. It should be noted that the hypophysectomized dogs had received no hormonal therapy for a month postoperatively and then received ACTH (30 units per day) for only three days prior to these studies. To what extent adrenal function was restored by this therapy is not known.

Cholesterol, phospholipid and triglyceride responses to epinephrine. Daily injections of epinephrine in oil have been shown to lead to progressive increases in serum levels of cholesterol and phospholipid $(2,3)$. In the present studies it was found that adrenalectomy or hypophysectomy reduced these lipid responses to a minimum or abolished them completely. The results are summarized in Tables I and II. The responses of individual dogs are shown before and after surgery and then on hormonal therapy.

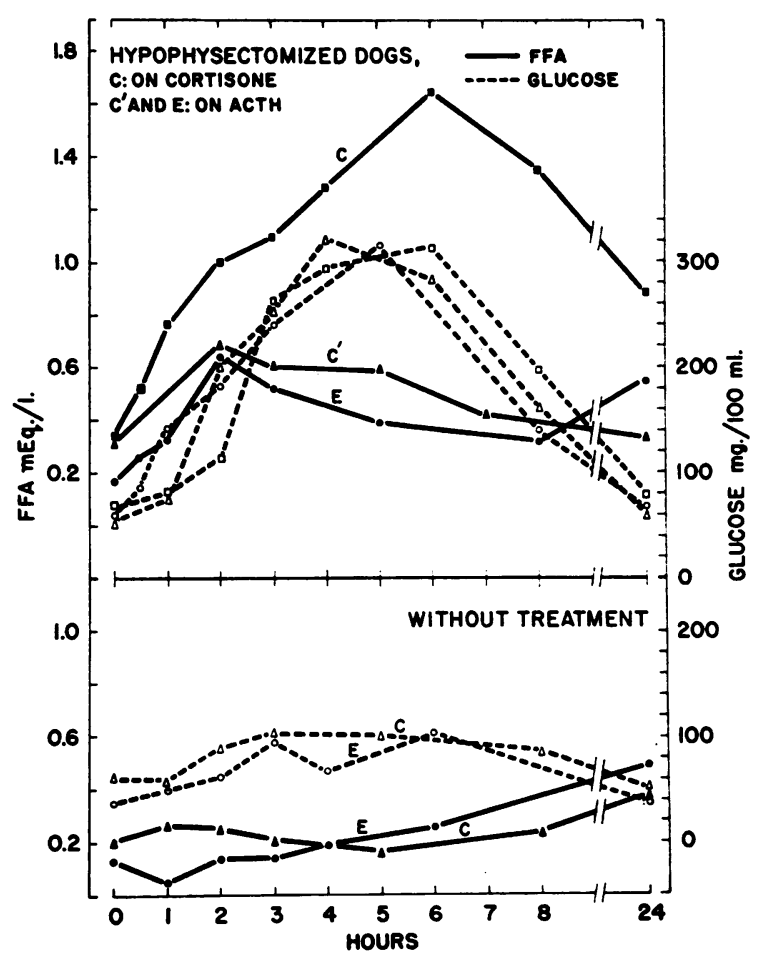

Fig. 6. Time course of FFA and glucose responses TO SUBCUTANEOUS INJECTION OF EPINEPHRINE IN OII (0.6 MG PER KG). Lower frame: hypophysectomized dogs given no treatment. Upper frame: same hypophysectomized dogs given cortisone or ACTH. 
TABLE I

Effects of adrenalectomy on plasma lipid responses to epinephrine

\begin{tabular}{|c|c|c|c|c|c|c|c|c|c|c|c|c|c|}
\hline \multirow[b]{3}{*}{ Dog } & \multirow{3}{*}{$\begin{array}{l}\text { Days of } \\
\text { epinephrine } \\
\text { treatment } \dagger\end{array}$} & \multicolumn{12}{|c|}{ Plasma lipid levels* $(\mathrm{mg}$ per $100 \mathrm{ml}$ ) } \\
\hline & & \multicolumn{4}{|c|}{ Before operation } & \multicolumn{4}{|c|}{ After operation on DCA only } & \multicolumn{4}{|c|}{$\begin{array}{c}\text { After operation on DCA } \\
\text { and cortisone } \neq\end{array}$} \\
\hline & & TC & FC & PL & TG & TC & FC & PL & TG & $\mathrm{TC}$ & FC & PL & TG \\
\hline \multirow{4}{*}{$T$} & $\begin{array}{l}\mathbf{0} \\
\mathbf{1}\end{array}$ & $\begin{array}{l}68 \\
79\end{array}$ & $\begin{array}{l}19 \\
25\end{array}$ & $\begin{array}{l}186 \\
237\end{array}$ & $\begin{array}{l}67 \\
71\end{array}$ & $\begin{array}{l}93 \\
94\end{array}$ & 32 & $\begin{array}{l}207 \\
222\end{array}$ & $\begin{array}{l}63 \\
60\end{array}$ & $\begin{array}{l}102 \\
118\end{array}$ & $\begin{array}{l}32 \\
41\end{array}$ & $\begin{array}{l}272 \\
334\end{array}$ & $\begin{array}{l}84 \\
84\end{array}$ \\
\hline & Percentage change & +16.2 & +31.5 & +27.4 & +6.2 & +1.1 & +3.1 & +7.2 & -5.0 & +15.7 & +28.0 & +22.8 & 0 \\
\hline & 3 & 88 & 26 & 272 & 63 & 100 & 33 & 235 & 50 & & & & \\
\hline & Percentage change & +29.4 & +36.8 & +46.2 & -6.0 & +7.5 & +3.1 & +13.5 & -20.6 & & & & \\
\hline \multirow{4}{*}{$\mathbf{P}$} & $\begin{array}{l}0 \\
1\end{array}$ & $\begin{array}{l}125 \\
146\end{array}$ & $\begin{array}{l}34 \\
45\end{array}$ & $\begin{array}{l}243 \\
343\end{array}$ & $\begin{array}{l}51 \\
57\end{array}$ & $\begin{array}{l}105 \\
115\end{array}$ & $\begin{array}{l}33 \\
37\end{array}$ & $\begin{array}{l}242 \\
253\end{array}$ & $\begin{array}{l}82 \\
61\end{array}$ & $\begin{array}{l}210 \\
241\end{array}$ & $\begin{array}{l}67 \\
70\end{array}$ & $\begin{array}{l}353 \\
374\end{array}$ & $\begin{array}{l}74 \\
41\end{array}$ \\
\hline & Percentage change & +16.8 & +32.7 & +41.2 & +11.8 & +9.5 & +12.1 & +4.5 & -25.6 & +14.8 & +4.5 & +6.0 & -44.6 \\
\hline & 3 & 165 & 53 & 301 & 68 & 115 & 34 & 253 & 71 & & & & \\
\hline & Percentage change & +32.0 & +55.9 & +23.9 & +33.3 & +9.5 & +3.3 & +4.5 & -13.4 & & & & \\
\hline \multirow[t]{2}{*}{ B } & $\begin{array}{l}0 \\
1\end{array}$ & $\begin{array}{l}125 \\
150\end{array}$ & $\begin{array}{l}36 \\
51\end{array}$ & $\begin{array}{l}293 \\
376\end{array}$ & $\begin{array}{l}64 \\
55\end{array}$ & & & & & $\begin{array}{l}139 \\
163\end{array}$ & $\begin{array}{l}40 \\
45\end{array}$ & $\begin{array}{l}325 \\
379\end{array}$ & $\begin{array}{l}54 \\
39\end{array}$ \\
\hline & Percentage change & +20.0 & +41.7 & +28.3 & -14.1 & & & & & +23.7 & +12.5 & +16.5 & -27.8 \\
\hline \multirow{4}{*}{$\mathrm{D}$} & $\begin{array}{l}0 \\
1\end{array}$ & & & & & $\begin{array}{l}133 \\
120\end{array}$ & $\begin{array}{l}40 \\
38\end{array}$ & $\begin{array}{l}258 \\
236\end{array}$ & $\begin{array}{l}55 \\
68\end{array}$ & & & & \\
\hline & Percentage change & & & & & -9.8 & -5.0 & -8.5 & +23.6 & & & & \\
\hline & 3 & & & & & 149 & 43 & 248 & 81 & & & & \\
\hline & Percentage change & & & & & +12.0 & +7.5 & -3.9 & +47.2 & & & & \\
\hline
\end{tabular}

$* \mathrm{TC}=$ total cholesterol $; \mathrm{FC}=$ free cholesterol $; \mathrm{PL}=$ phospholipids $; \mathrm{TG}=$ triglycerides.

+ Daily injections of epinephrine in oil $(0.6 \mathrm{mg}$ per $\mathrm{kg})$.

¥ Cortisone ( 3 to $5 \mathrm{mg}$ per $\mathrm{kg}$ per day) given for $7 \mathrm{~kg}$ to 10 days prior to and during epinephrine study.

In all cases the cholesterol and phospholipid responses after adrenalectomy were sharply reduced. Before operation the mean rise of total cholesterol in three dogs given a single injection of epinephrine was 17.7 per cent. After operation the mean rise was 6.2 per cent. When three daily doses of epinephrine were given the difference was more marked, the intact animals showing elevations of 29.4 and 32.0 per cent, while the same animals after adrenalectomy showed elevations of only 7.5 and 9.5 per cent. The epinephrine-induced changes in free cholesterol and phospholipid levels were similarly suppressed by adrenalectomy.

When adrenalectomized animals were maintained on cortisone the cholesterol responses to epinephrine injection were similar to those observed prior to adrenalectomy (mean elevation 18.1 per cent on cortisone compared with 17.7

TABLE II

Effects of hypophysectomy on plasma lipid responses to epinephrine

\begin{tabular}{|c|c|c|c|c|c|c|c|c|c|c|c|c|c|}
\hline \multirow[b]{3}{*}{ Dog } & \multirow{3}{*}{$\begin{array}{c}\text { Days of } \\
\text { epinephrine } \\
\text { treatment } \dagger\end{array}$} & \multicolumn{12}{|c|}{ Plasma lipid levels* (mg per $100 \mathrm{ml}$ ) } \\
\hline & & \multicolumn{4}{|c|}{ Before operation } & \multicolumn{4}{|c|}{ After operation; no therapy } & \multicolumn{4}{|c|}{ After operation; on ACTH } \\
\hline & & TC & FC & PL & TG & $\mathrm{TC}$ & FC & $\mathrm{PL}$ & TG & $\mathrm{TC}$ & FC & PL & TG \\
\hline \multirow[t]{2}{*}{$\mathrm{E}$} & $\begin{array}{l}0 \\
1 \\
3\end{array}$ & $\begin{array}{r}78 \\
98 \\
119\end{array}$ & $\begin{array}{l}25 \\
33 \\
39\end{array}$ & $\begin{array}{l}171 \\
234 \\
222\end{array}$ & $\begin{array}{l}56 \\
61 \\
62\end{array}$ & $\begin{array}{r}102 \\
101 \\
89\end{array}$ & $\begin{array}{l}31 \\
34 \\
30\end{array}$ & $\begin{array}{l}198 \\
220 \\
177\end{array}$ & $\begin{array}{l}39 \\
50 \\
38\end{array}$ & $\begin{array}{l}62 \\
72 \\
96\end{array}$ & $\begin{array}{l}18 \\
24 \\
27\end{array}$ & $\begin{array}{l}145 \\
166 \\
222\end{array}$ & $\begin{array}{l}40 \\
57 \\
44\end{array}$ \\
\hline & Percentage change & +53.0 & +55.4 & +29.5 & +10.5 & -12.7 & -3.3 & -10.6 & -2.8 & +54.9 & $+\mathbf{5 0 . 0}$ & +53.1 & +10.0 \\
\hline \multirow[t]{2}{*}{ C } & $\begin{array}{l}0 \\
1 \\
3\end{array}$ & $\begin{array}{r}89 \\
112 \\
143\end{array}$ & $\begin{array}{l}24 \\
33 \\
42\end{array}$ & $\begin{array}{l}205 \\
285 \\
270\end{array}$ & $\begin{array}{l}73 \\
88 \\
80\end{array}$ & $\begin{array}{l}115 \\
125 \\
138\end{array}$ & $\begin{array}{l}34 \\
38 \\
41\end{array}$ & $\begin{array}{l}222 \\
253 \\
245\end{array}$ & $\begin{array}{l}37 \\
41 \\
34\end{array}$ & $\begin{array}{l}115 \\
134 \\
161\end{array}$ & $\begin{array}{l}37 \\
43 \\
49\end{array}$ & $\begin{array}{l}253 \\
291 \\
330\end{array}$ & $\begin{array}{l}69 \\
58 \\
53\end{array}$ \\
\hline & Percentage change & +60.7 & +75.0 & +31.7 & +9.6 & +15.3 & +20.6 & +10.4 & -8.1 & +40.0 & +32.5 & +30.5 & -23.2 \\
\hline
\end{tabular}

$* \mathrm{TC}=$ total cholesterol $; \mathrm{FC}=$ free cholesterol $; \mathrm{PL}=$ phospholipids; $\mathrm{TG}=$ triglycerides.

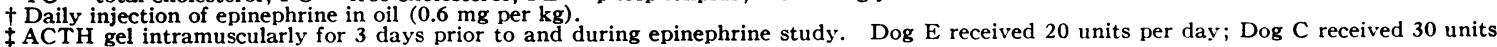
per day. 
TABLE III

Potentiation by cortisone of the plasma lipid responses to epinephrine in normal dogs

\begin{tabular}{|c|c|c|c|c|c|c|c|c|c|}
\hline \multirow[b]{3}{*}{ Dog } & \multirow{3}{*}{$\begin{array}{c}\text { Days of } \\
\text { epinephrine } \\
\text { treatment }\end{array}$} & \multicolumn{8}{|c|}{ Plasma lipid levels* (mg per $100 \mathrm{ml}$ ) } \\
\hline & & \multicolumn{4}{|c|}{ Epinephrine alone } & \multicolumn{4}{|c|}{ Epinephrine with cortisonef } \\
\hline & & TC & FC & PL & TG & TC & FC & PL & TG \\
\hline \multirow[t]{2}{*}{$\mathrm{Ca}$} & $\begin{array}{l}0 \\
1 \\
3\end{array}$ & $\begin{array}{l}100 \\
117 \\
151\end{array}$ & $\begin{array}{l}28 \\
40 \\
45\end{array}$ & $\begin{array}{l}274 \\
325 \\
334\end{array}$ & $\begin{array}{l}62 \\
42 \\
68\end{array}$ & $\begin{array}{l}117 \\
159 \\
219\end{array}$ & $\begin{array}{l}34 \\
49 \\
64\end{array}$ & $\begin{array}{l}333 \\
433 \\
428\end{array}$ & $\begin{array}{l}64 \\
58 \\
61\end{array}$ \\
\hline & Percentage change & +51.0 & +60.7 & +21.9 & +9.7 & +87.1 & +88.3 & +28.5 & -4.7 \\
\hline \multirow[t]{2}{*}{ M } & $\begin{array}{l}0 \\
1 \\
3\end{array}$ & $\begin{array}{l}112 \\
127 \\
155\end{array}$ & $\begin{array}{l}30 \\
36 \\
45\end{array}$ & $\begin{array}{l}251 \\
305 \\
350\end{array}$ & $\begin{array}{l}48 \\
33 \\
53\end{array}$ & $\begin{array}{l}140 \\
188 \\
254\end{array}$ & $\begin{array}{l}45 \\
67 \\
81\end{array}$ & $\begin{array}{l}301 \\
424 \\
408\end{array}$ & $\begin{array}{l}49 \\
61 \\
55\end{array}$ \\
\hline & Percentage change & +38.5 & +50.0 & +40.3 & +10.4 & +81.4 & +80.0 & +35.6 & +12.2 \\
\hline
\end{tabular}

* $\mathrm{TC}=$ total cholesterol $; \mathrm{FC}=$ free cholesterol $; \mathrm{PL}=$ phospholipids $; \mathrm{TG}=$ triglycerides.

$\dagger$ Daily injections of epinephrine in oil $(0.6 \mathrm{mg}$ per $\mathrm{kg})$.

$\ddagger$ Daily injections of epinephrine in oil $(0.6 \mathrm{mg}$ per $\mathrm{kg})$ plus cortisone $(5 \mathrm{mg}$ per $\mathrm{kg})$.

per cent in the same three animals prior to surgery). The phospholipid responses were partially restored but appeared to be somewhat smaller than the responses of the intact animals.

In order to determine to what extent cortisone itself might be contributing to the lipid responses induced by the combined epinephrine and cortisone treatment, four of the adrenalectomized dogs were given cortisone alone. The mean rise in total plasma cholesterol level occurring in 24 hours was 2.7 per cent and the maximum rise 3.6 per cent. The mean rise in phospholipid level was 6.8 per cent and the maximum rise 14.4 per cent. Thus it is clear that although prolonged cortisone therapy can importantly influence plasma lipid levels, the acute changes occurring over the short intervals used in these studies are not to any extent due to a direct action of cortisone. It appears that the effect of cortisone is not simply additive but rather permissive.

As shown in Table II, hypophysectomy also abolished or markedly reduced the cholesterol and phospholipid responses to epinphrine. Treatment with ACTH fully restored these responses to normal. The effects of ACTH itself were studied in Dogs $\mathrm{E}$ and $\mathrm{C}$. Treatment for three days raised the plasma cholesterol levels only 4.6 and 4.8 per cent, the phospholipid levels 13.1 and 18.0 per cent. It can be concluded that in these studies the action of ACTH, like that of cortisone, is not an additive effect but a permissive or synergistic effect. Its effectiveness may well be en- tirely or in part secondary to its stimulation of adrenal function.

For a number of reasons it is difficult to evaluate properly the changes in triglyceride levels. As discussed in a previous paper (3), the triglyceride values in untreated, normal dogs can fluctuate very widely over a 24 hour period. Furthermore, the analytical method for this lipid component depends upon a difference calculation (7), and the results are probably not more accurate than \pm 10 per cent. No statistical evaluation can be applied to the small number of data included in the present study but it is clear that the triglyceride responses have been considerably more variable than the responses of the other lipids and lesser in magnitude. It is doubtful whether any significance can be attributed to the changes in triglyceride values.

Finally, the effect of cortisone on the epinephrine responses of normal dogs was studied. The potentiation of the FFA responses has already been described (Figure 4, top frame). The equally striking potentiation of the cholesterol and phospholipid responses is shown in Table III. In the case of Dog C the cholesterol level rose from 117 $\mathrm{mg}$ per $100 \mathrm{ml}$ to a level of $219 \mathrm{mg}$ per $100 \mathrm{ml}$ on three days of combined treatment; in Dog M the absolute levels were $140 \mathrm{mg}$ per $100 \mathrm{ml}$ before treatment and $254 \mathrm{mg}$ per $100 \mathrm{ml}$ after three days of treatment. As shown by Adlersberg, Drachman and Schaefer (9), and confirmed in this laboratory, three days' treatment with cortisone alone does not 
cause significant elevation of plasma lipid levels in normal dogs. The cortisone effect is thus not an additive one but rather permissive in nature.

\section{DISCUSSION}

It has been demonstrated previously in rats (2) and now in dogs that the lipid mobilization induced by epinephrine is dependent upon intact adrenal function. Both the FFA and the lipoprotein responses to epinephrine were abolished in adrenalectomized dogs maintained on DCA alone. Both were restored when the adrenalectomized dogs were given supportive cortisone therapy. Since short-term treatment with cortisone alone in similar dosages had little effect it appears that its role in the epinephrine response is permissive and not simply additive. Independent studies by Reshef and Shapiro on FFA release from mesenteric adipose tissue incubated in vitro have led to the same conclusion (10).

Hypophysectomy, like adrenalectomy, abolished both the FFA and the lipoprotein responses to epinephrine. Since the time interval between surgery and the epinephrine studies (one week) was long enough to permit considerable involution of the adrenal gland, the failure to respond might be partly or entirely attributable to secondary adrenal insufficiency. The fact that treatment with cortisone alone fully restored the FFA and lipoprotein responses is compatible with this possibility. On the other hand, treatment with ACTH, while it fully restored the lipoprotein response, only partially restored the FFA response. It is possible that hypophysectomy deprives the animal of other pituitary factors involved in lipid mobilization. While the present studies were in progress, Goodman and Knobil (11) reported that hypophysectomy in rhesus monkeys abolished the FFA response to epinephrine in oil. The response was partially restored by pretreatment with thyroidstimulating hormone and fully restored by pretreatment with L-triodothyronine. Pretreatment with cortisol acetate or ACTH, on the other hand, was ineffective, in apparent disagreement with the present results. The difference in results may reflect the longer time interval (two months) between hypophysectomy and the tests of responsiveness in Goodman and Knobil's experiments. This would allow for more complete loss of thyroid function, which appears in their studies to play a role in FFA mobilization. Rudman and Seidman (12) and Seifter and Baeder (13) have described lipid mobilizing factors from the pituitary believed to be distinct from any of the known purified pituitary hormones. Whether or not the loss of pituitary factors such as these modified the ability of the hypophysectomized animals to respond to epinephrine cannot be decided at the present time.

The fact that adrenalectomized animals have a low fasting plasma FFA level and that they respond poorly to stimuli which in the intact animal produce an outpouring of FFA from the fat depots may help to explain a number of earlier observations on fat mobilization. The development of a fatty liver, often used as a measure of fat mobilization, has been repeatedly demonstrated to depend upon adrenal function. In 1936, Verzar and Laszt showed that phosphorus poisoning failed to produce fatty livers in adrenalectomized rats but that after treatment with adrenocortical extracts results were comparable to those seen in intact control animals (14). In similar fashion it has been shown that the fatty liver due to exposure to cold (15), prolonged fasting (15), treatment with ethionine (16), and treatment with epinephrine (17) can be produced only in the presence of the adrenal glands. Treatment of adrenalectomized animals with corticosteroids in each case restored the ability of the adrenalectomized animals to develop fatty liver in response to these stimuli. Of particular importance in this connection are the results of Wool, Goldstein, Ramey and Levine (18), demonstrating that the removal of the adrenal medulla or treatment with ergotamine also inhibits the development of fatty liver in animals fed ethionine. They concluded that adrenomedullary function as well as adrenocortical function was essential to the lipid mobilization induced by ethionine. It may be that some of the other forms of treatment used to induce fatty liver also depend on medullary as well as cortical function. On the basis of the present studies it seems reasonable to suggest that these and similar results can be attributed to the inability of the adrenalectomzied animal to mobilize fatty acids from adipose tissue at a rate sufficient to lead to accumulation of liver fat.

Another well documented finding implicating the adrenal gland in fat metabolism is the observa- 
tion that the ketonuria induced by injection of anterior pituitary extracts is reduced or abolished by adrenalectomy and is restored by treatment with adrenocortical extracts (19). Evans found that adrenodemedullation considerably reduced the ketonuria observed after phloridzin treatment (20). While these results may be due in part to other effects on metabolic patterns it is also possible that the role of the adrenal glands is simply to permit sufficiently rapid mobilization of substrate fatty acids from the depots.

The loss of the hyperglycemic response to epinephrine in adrenalectomized and in hypophysectomized animals reported here confirms previous observations of a similar nature (21). Responsiveness is partially or completely restored by administration of adrenocortical steroids (22) and this, too, is confirmed. These observations may be explained wholly or in part by the fact that the level of liver glycogen is lower in adrenalectomized animals. On the other hand the parallel loss of FFA response and glucose response suggests that adrenocortical steroids may play a similar permissive role in both the adipose tissue and the liver.

In the present studies there is a striking parallelism between factors influencing the FFA response to epinephrine and the lipoprotein response to epinephrine. It is difficult to avoid the conclusion that the two responses stem from a common primary action of epinephrine or that the mobilization of FFA, the earliest effect, is itself the basis for the subsequent elevation of plasma lipoprotein levels. Specifically, it can be postulated that the increase in liver lipids due to transfer of fatty acids from the depots may constitute an adequate stimulus to the subsequent production and release of lipoproteins into the serum. The only observation incompatible with this hypothesis is the partial dissociation between the two lipid responses to epinephrine observed previously when large amounts of glucose were administered along with the epinephrine (3). Here, however, the dissociation was incomplete and the possible independent effects of glucose administration were not examined. Studies of the fate of FFA reaching the liver in increased quantities may help to clarify the interrelationship of FFA mobilization and lipoprotein mobilization.

The remarkable potentiation by cortisone of the lipoprotein response of intact animals to epineph- rine may have important implications with respect to the hypercholesterolemia observed under conditions of physical or emotional stress. Under stress the adrenal gland increases its output both of epinephrine from the medulla and steroids from the cortex (23). The combined action of these hormones, as shown above, is capable of almost doubling the serum cholesterol level of dogs over a period of three days. Friedman, Rosenman and Carroll (24), Thomas and Murphy (25) and Wertlake, Wilcox, Haley and Peterson (26) have recently reported on the elevation of serum cholesterol levels observed in patients subject to emotional stress. Cardon and Gordon (27) and Bogdonoff, Estes and Trout (28) have shown that patients subjected to the stress of a frightening situation exhibit a sharp rise in circulating FFA.

It is suggested that, at least in part, the mechanism by which psychic factors in these and similar studies manifest themselves somatically in the form of elevated blood cholesterol levels is neurohumoral in nature, i.e., autonomic stimulation of adrenomedullary function and hypothalamic-pituitary stimulation of adrenocortical function. The work of Havel and Goldfien (29) suggests that activity of the sympathetic nervous system is of importance in the control of FFA mobilization in the normal individual. It may also be important in controlling serum lipoprotein levels.

\section{SUM M ARY}

1. In normal dogs intravenous injection of aqueous epinephrine ( 20 to $25 \mu \mathrm{g}$ per $\mathrm{kg}$ ) caused an elevation of plasma free fatty acids (FFA) maximal at 5 to 10 minutes and returning to normal levels at about 20 minutes. An immediate (two minute) but very transient fall in FFA was interpreted as a reflection of an increased rate of utilization of FFA, temporarily exceeding the rate of FFA release from the depots.

2. After adrenalectomy or after hypophysectomy the same dogs given the same doses of epinephrine failed to show any elevation of plasma FFA. Treatment with cortisone, however, completely restored the FFA responses to levels similar to those seen preoperatively.

3. In normal dogs subcutaneous injection of epinephrine in oil $(0.6 \mathrm{mg}$ per $\mathrm{kg}$ ) caused an elevation of plasma FFA maximal at two to three hours 
and returning to normal levels at about six hours. Twenty-four hours later plasma cholesterol and phospholipid levels were significantly elevated. After three daily injections of epinephrine in oil, cholesterol levels had risen 29 to 61 per cent and phospholipid levels 22 to 46 per cent over control levels. The changes in triglyceride levels were not consistent.

4. After adrenalectomy or after hypophysectomy the FFA, cholesterol, and phospholipid responses to injection of epinephrine in oil were abolished completely or reduced to very low levels. Treatment of adrenalectomized dogs with cortisone restored the FFA, cholesterol, and phospholipid responses to levels comparable with those seen preoperatively. Treatment of hypophysectomized dogs with cortisone fully restored the FFA response to epinephrine; treatment with adrenocorticotropic hormone partially restored the FFA response and completely restored the cholesterol and phospholipid responses to epinephrine.

5. Administration of cortisone to normal dogs considerably potentiated the plasma FFA response, elevated levels persisting for up to 24 hours. The elevations of cholesterol and phospholipid levels at 24 hours were also considerably greater than those resulting from injection of epinephrine alone.

6. It was concluded that the mobilization of FFA and of lipoproteins by epinephrine is dependent upon intact adrenal function and in particular on the simultaneous availability of cortisone or cortisone-like steroids. Whether the effects of hypophysectomy are all secondary to subsequent involution of the adrenal gland could not be decided.

7. It is suggested that the hypercholesterolemia of stress reported in man may in part be due to the accompanying overactivity of the adrenal medulla and adrenal cortex, simultaneously introducing epinephrine and corticosteroids into the system in analogy with the present studies in dogs.

\section{ACKNOWLEDGMENTS}

The authors gratefully acknowledge the assistance of Dr. John E. Holman in the performance of adrenalectomies, of Mr. Alfred G. T. Casper in the performance of hypophysectomies, and of Mr. Carl J. Lauter and Mr. Edward H. Mougey in the performance of lipid analyses.

\section{REFERENCES}

1. Shafrir, E., Sussman, K. E., and Steinberg, D. Mobilization of lipids in epinephrine treated, adrenal- ectomized and hypophysectomized animals (abstract). Fed. Proc. 1959, 18, 321.

2. Shafrir, E., Sussman, K. E., and Steinberg, D. The role of the pituitary and the adrenal in the mobilization of free fatty acids and lipoproteins. J. lip. Res. In press.

3. Shafrir, E., Sussman, K. E., and Steinberg, D. The nature of the epinephrine-induced hyperlipidemia in dogs and its modification by glucose. J. lip. Res. 1959, 1, 109.

4. Gordon, R. S., Jr. Unesterified fatty acid in human blood plasma. II. The transport function of unesterified fatty acid. J. clin. Invest., 1957, 36, 810.

5. Sperry, W. M., and Webb, M. A revision of the Schoenheimer-Sperry method for cholesterol determination. J. biol. Chem. 1950, 187, 97.

6. Stewart, C. P., and Hendry, E. B. The phospholipids of blood. Biochem. J. 1935, 29, 1683.

7. Bragdon, J. H. Colorimetric determination of blood lipides. J. biol. Chem. 1951, 190, 513.

8. Nelson, N. A photometric adaptation of the Somogyi method for the determination of glucose. J. biol. Chem. 1944, 153, 375.

9. Adlersberg, D., Drachman, S. R., and Schaefer, L. E. Effects of cortisone and ACTH on serum lipids in animals: Possible relationship to experimental atherosclerosis (abstract). Circulation 1951, 4, 475.

10. Reshef, L., and Shapiro, B. The effect of adrenaline, cortisone and growth hormone on the release of unesterified fatty acids by adipose tissue in vitro. Metabolism. In press.

11. Goodman, H. M., and Knobil, E. Mobilization of fatty acids by epinephrine in normal and hypophysectomized rhesus monkeys. Proc. Soc. exp. Biol. (N. Y.) 1959, 100, 195.

12. Rudman, D., and Seidman, F. Lipemia in the rabbit following injection of pituitary extract. Proc. Soc. exp. Biol. (N. Y.) 1958, 99, 146.

13. Seifter, J., and Baeder, D. H. Lipid mobilizer (LM) from posterior pituitary of hogs. Proc. Soc. exp. Biol. (N. Y.) 1957, 95, 318.

14. Verzar, F., and Laszt, L. Nebennierenrinde und Fettwanderung. Biochem. Z. 1936, 288, 356.

15. LeBlond, C. P., Thoai, Nguyen-van, and Segal, G. Infiltration graisseuse du foie sous l'action des agents nocifs. C. R. Soc. Biol. (Paris) 1939, 130, 1557.

16. Wool, I. G., and Goldstein, M. S. Role of neurohumors in the action of the adrenal cortical steroids : Mobilization of fat. Amer. J. Physiol. 1953, 175, 303.

17. MacKay, E. M. Influence of adrenalectomy on liver fat as varied by diet and other factors. Amer. J. Physiol. 1937, 120, 361.

18. Wool, I. G., Goldstein, M. S., Ramey, E. R., and Levine, R. Role of epinephrine in the physiology of fat mobilization. Amer. J. Physiol. 1954, 178, 427. 
19. Fry, E. G. The effect of adrenalectomy and thyroidectomy on ketonuria and liver fat content of the albino rat following injections of anterior pituitary extract. Endocrinology 1937, 21, 283.

20. Evans, G. Response of adrenalectomized rats to phloridzination. Proc. Soc. exp. Biol. (N. Y.) 1935, 32, 1246.

21. Ellis, S. The metabolic effects of epinephrine and related amines. Pharmacol. Rev. 1956, 8, 485.

22. DeBodo, R. C., Sinkoff, M. W., Kiang, S. P., and Den, H. Prevention of growth hormone-induced diabetes in hypophysectomized dogs by adrenocortical steroids. Proc. Soc. exp. Biol. (N. Y.) 1952, 81, 425.

23. Long, C. N. H. The conditions associated with the secretion of the adrenal cortex. Fed. Proc. 1947, 6, 461.

24. Friedman, M., Rosenman, R. H., and Carroll, V. Changes in the serum cholesterol and blood clotting time in men subjected to cyclic variation of occupational stress. Circulation 1958, 17, 852.

25. Thomas, C. B., and Murphy, E. A. Further studies on cholesterol levels in the Johns Hopkins medical students: The effect of stress at examinations. J. chron. Dis. 1958, 8, 661 .

26. Wertlake, P. T., Wilcox, A. A., Haley, M. I., and Peterson, J. E. Relationship of mental and emotional stress to serum cholesterol levels. Proc. Soc. exp. Biol. (N. Y.) 1958, 97, 163.

27. Cardon, P. V., Jr., and Gordon, R. S., Jr. Rapid increase of plasma unesterified fatty acids in man during fear. J. psychosom. Res. 1959, 4. In press.

28. Bogdonoff, M. D., Estes, E. H., Jr., and Trout, D. Acute effect of psychological stimuli upon plasma non-esterified fatty acid level. Proc. Soc. exp. Biol. (N. Y.) 1959, 100, 503.

29. Havel, R. J., and Goldfien, A. The role of the sympathetic nervous system in the metabolism of free fatty acids. J. lip. Res. 1959, 1, 102. 